\title{
Albumin induces CD44 expression in glomerular parietal epithelial cells by activating ERK signaling pathway
}

\author{
Xueying Zhao, Xiaoming Chen, Ashmeer Chima, Yuanyuan Zhang, Jasmine George, Alyssa \\ Cobbs, and Nerimiah Emmett \\ Department of Physiology, Morehouse School of Medicine, Atlanta, GA 30310
}

\begin{abstract}
De novo expression of CD44 in glomerular parietal epithelial cells (PECs) leads to a pro-sclerotic and migratory PEC phenotype in glomerulosclerosis. However, the regulatory mechanisms underlying CD44 expression by activated PECs remain largely unknown. This study was performed to examine the mediators responsible for CD44 induction in glomerular PECs in association with diabetes. CD44 expression and localization were evaluated in the glomeruli of Zucker diabetic rat kidneys and primary cultured PECs upon albumin stimulation. Real-time polymerase chain reaction confirmed an albuminuria-associated upregulation of the CD44 gene in the glomeruli of diabetic rats. Immunostaining analysis of diabetic kidneys further revealed an increase in CD44 in hypertrophic PECs, which often contain albumin-positive vesicles. Losartan treatment significantly attenuated albuminuria and lowered CD44 protein levels in the diabetic kidneys. In primary cultured rat PECs, rat serum albumin $(0.25-1 \mathrm{mg} / \mathrm{ml})$ caused a dosedependent upregulation of CD44, claudin-1, and megalin protein expression, which was accompanied by an activation of ERK1/2 signaling. Albumin-induced CD44 and claudin-1 expression was greatly suppressed in the presence of the ERK1/2 inhibitor, U0126. Additionally, knockdown of megalin by siRNA interference in PECs resulted in a significant reduction of albumin-induced CD44 and claudin-1 proteins. Taken together, our results demonstrate that albumin induces CD44 expression by PECs via the activation of the ERK signaling pathway, which is partially mediated by endocytic receptor megalin.
\end{abstract}

\section{Keywords}

diabetic glomerular disease; albuminuria; U0126; megalin; parietal epithelial cells

\section{Introduction}

Diabetic kidney disease is the leading cause of end-stage renal disease in the United States and many other developed countries. In diabetic glomerular disease, early microalbuminuria due to glomerular filtration barrier dysfunction often progresses to proteinuria and ultimately leads to a decline in excretory renal function associated with renal fibrosis (Nangaku,

Corresponding author: Dr. Xueying Zhao, Department of Physiology, Morehouse School of Medicine, Atlanta, GA 30310, Tel: 404-752-1902, Fax: 404-752-1045, xzhao@msm.edu.

Conflicts of interest

The authors declare that there are no conflicts of interest regarding the publication of this paper. 
2004; Abbate et al, 2006). Excessive reabsorption of filtered albumin by glomerular and tubular epithelial cells is involved in the development and progression of renal inflammation, fibrosis, and loss of excretory function (Dinneen and Gerstein, 1997; Lin and Susztak, 2016). Recently, potential roles of parietal epithelial cells (PECs) in glomerular cell damage and regeneration have been highlighted in different glomerular diseases (Lim et al, 2016). For instance, after glomerular podocyte loss, PECs could be a source of podocyte repopulation as both cell types have common mesenchymal progenitors. However, activated PECs could proliferate, migrate, and produce extracellular matrix, contributing to the development and progression of glomerular sclerosis.

CD44, a widely distributed cell surface glycoprotein, has been shown to mediate cell adhesion and migration in a variety of pathophysiological processes including tumor metastasis, wound healing, and inflammation (Marhaba and Zoller, 2004). Although CD44 expression in normal mouse and human glomeruli is negligible, its level is increased in sclerotic mouse glomeruli and biopsies from patients with glomerular sclerosis (Eymael et al, 2017;Fatima et al, 2012;Froes et al, 2017;Kim et al, 2016;Okamoto et al, 2013;Roeder et al, 2017; Yamazaki et al, 2016). An increase in CD44-positive PECs was associated with podocyte dysregulation and glomerular filtration rate (GFR) decline in progressive kidney disease (Froes et al, 2017). Recent studies have also demonstrated that increased CD44 protein leads to a prosclerotic and migratory PEC phenotype (Roeder et al, 2017) and that CD44 is required for the pathogenesis of experimental crescentic glomerulonephritis and collapsing focal segmental glomerulosclerosis (Eymael et al, 2017). Roeder et al. have shown that activated ERK1/2 is a regulator of CD44 in PECs. However, it remains unclear what causes PEC activation and CD44 upregulation in diabetic glomerular disease.

Among the factors that influence the maladaptive PEC response, ultrafiltered albumin has been regarded as a critical player that activates PECs and initiates an injury response. Excessive albumin uptake by podocytes and tubular epithelial cells can occur in a megalindependent manner (Amsellem et al, 2010; Chatelet et al, 1986; Schiessl et al, 2016;Zhang et al, 2015). Glomerular and tubular reabsorption of albumin has been shown to induce the production of a variety of proinflammatory and profibrotic cytokines such as RANTES (Zoja et al, 1998), monocyte chemoattractant protein-1 (Takaya et al, 2003; Wang et al, 1999), transforming growth factor- $\beta$ (TGF- $\beta$ ) (Diwakar et al, 2007; Yard et al, 2001), and matrix metalloproteinase-9 (Chen et al, 2017;Zhang et al, 2015). Therefore, we hypothesized that albumin overload could stimulate CD44 expression by activated PECs.

We first performed real-time PCR, immunofluorescence staining, and Western blot analyses to evaluate the relationship between albumin overload and CD44 expression in the glomeruli of Zucker diabetic rats in the absence or presence of anti-proteinuric interference. To determine if albumin could stimulate CD44 expression, primary cultured rat PECs were exposed to rat serum albumin, mimicking proteinuria related damage. In vitro cell culture studies were also performed to investigate the role of the ERK signaling pathway and endocytic receptor megalin in CD44 expression by activated PECs. 


\section{Materials and methods}

\section{Experimental animals}

Male Zucker lean (ZL) and Zucker diabetic (ZD) rats were purchased from Charles River Laboratories (Wilmington, MA, USA) and housed in a temperature-controlled room with a 12:12-hour light-dark cycle and free access to Purina 5008 rat chow and water. Tail-vein blood was sampled for the measurement of blood glucose using the Accu-chek glucometer. Urine was collected over a 24-hour period in metabolic cages, and urinary albumin was measured by a commercial Nephrat kit (Exocell, Philadelphia, PA, USA). In a set of experiments, 12-week-old ZL and ZD rats were given $30 \mathrm{mg} / \mathrm{kg} /$ day losartan, an angiotensin II type 1 receptor antagonist, in drinking water for 8 weeks. Animals were housed in the animal care facility at the Morehouse School of Medicine. All animal protocols were approved by the Institutional Animal Care and Use Committee and were in accordance with the requirements stated in the National Institutes of Health Guide for the Care and Use Laboratory Animals.

\section{Primary culture of rat PECs}

Glomeruli were isolated from 6 to 10-week-old Sprague-Dawley rat kidneys as described previously (Zhao et al, 2011). Collected glomeruli were suspended in DMEM/F12 medium supplemented with $10 \%$ fetal bovine serum, penicillin, and streptomycin (Thermo Fisher Scientific, Carlsbad, CA, USA). To test the effect of albumin on CD44 expression, 80-90\% confluent PECs (day 6-7) were washed with serum-free DMEM and incubated in 2\%FBS/ DMEM/F12 medium with globulin-free or fatty acid-free rat serum albumin (RSA, Sigma Aldrich Inc., St. Louis, MO, USA) at varying concentrations $(0,0.25,0.5$, or $1 \mathrm{mg} / \mathrm{ml})$ for 24-72 hours. To evaluate the effect of ERK1/2 and PI3K activation on albumin-induced CD44, the cells were incubated with $0.5 \mathrm{mg} / \mathrm{ml}$ RSA in the presence of U0126 [1,4diamino-2,3-dicyano-1,4-bis (o-aminophenylmercapto) butadiene] (an ERK1/2 inhibitor, Sigma-Aldrich) or LY294002 (a PI3K inhibitor, Sigma-Aldrich). Following the treatment, the cell lysates were prepared using either RIPA or phosphosafe protein extraction buffer containing a cocktail of protease inhibitors (Sigma Aldrich Inc.). The samples were stored at $-80^{\circ} \mathrm{C}$ for Western blot analysis.

To evaluate the effect of high glucose on CD44 expression, primary PECs were incubated with 2\%FBS/DMEM/F12 containing either 5 or $30 \mathrm{mM}$ D-glucose medium for 24 or 72 hours. The effect of hyperosmolality was assessed in PECs cultured in DMEM/F-12 containing $5 \mathrm{mM}$ D-glucose supplemented with $25 \mathrm{mM}$ mannitol. The effect of TGF- $\beta 1$ was also determined by incubating the PECs with $4 \mathrm{ng} / \mathrm{ml}$ of TGF- $\beta 1$. Protein samples were collected and processed as above.

\section{Transfection of small interfering RNA (siRNA)}

Primary cultured PECs were transiently transfected with a validated non-targeting siRNA (scrambled control) or with a siRNA specific for megalin. All siRNAs were purchased from Thermo Fisher Scientific and transfected into the cells using Lipofectamine RNAiMAX reagent (Thermo Fisher Scientific) according to the manufacturer's instructions. 48 hours 
later, the cells were incubated with $0.5 \mathrm{mg} / \mathrm{ml}$ RSA for another 24 hours. Cellular protein was extracted and the reduction in protein expression was assessed by Western blot analysis.

\section{Taqman and quantitative real-time PCR analysis}

Total RNA was prepared from glomeruli isolated from ZL and ZD rats using ultra-pure TRIzol reagent according to the manufacturer's instructions (Gibco Laboratories, Gaithersburg, MD, USA). CD44 and $\beta$-actin gene-specific Taqman probe and primer sets were obtained from Applied Biosystems (Applied Biosystems Ins., Foster City, CA, USA) as Assays-on-Demand gene expression products. The Assays-on-Demand identification numbers were Rn00681157_m1 for CD44 and 4331182 for rat $\beta$-actin endogenous control. Each sample was run in triplicate, and the comparative threshold cycle $\left(\mathrm{C}_{\mathrm{t}}\right)$ method was used to quantify fold increase $\left(2^{-\Delta \Delta C t}\right)$ compared with lean controls.

\section{Immunofluorescence staining}

To examine the expression pattern of CD44, dual labeling was performed by incubating frozen kidney sections with a mixture of two antibodies overnight: sheep anti-CD44 (1:100; R\&D Systems, Minneapolis, MN, USA) and rabbit anti-claudin-1 (1:100; abcam, Cambridge, MA, USA), mouse anti-CD44 and sheep anti-rat albumin (1:200; Bethyl Laboratories, Inc., Montgomery, TX, USA), or sheep anti-CD44 and rabbit anti-megalin (1:100; abcam). The secondary antibodies were Alexa Fluor 488-conjugated donkey anti sheep/rabbit/mouse IgG (1:200) or Alexa Fluor 555-conjugated donkey anti sheep/mouse/ rabbit IgG (1:200) from Jackson ImmunoResearch Laboratories (West Grove, PA, USA). As a negative control, the sections were exposed to nonimmune $\operatorname{IgG}$ (in replacement of primary antibodies) with the same secondary antibodies, and no specific staining was observed. After nuclear staining with DAPI, the slides were mounted with ProLong gold antifade reagent (Thermo Fisher Scientific). The sections were observed and imaged by Leica confocal microscope.

\section{Western blot analysis}

Kidney cortex homogenates or cell lysates were separated by 10\% SDS-PAGE and transferred electrophoretically to a nitrocellulose membrane. The blots were incubated with primary antibodies for CD44, claudin-1, megalin, or $\beta$-actin (Sigma Aldrich Inc.). The secondary antibodies were HRP-conjugated anti-sheep IgG or anti-rabbit IgG. For phosphoprotein analysis, the membranes were first hybridized with phospho-specific antibodies for ERK1/2, p38, and Akt (Cell Signaling Technology, Danvers, MA, USA), then stripped and reprobed with an antibody recognizing total ERK1/2, p38 or Akt (Cell Signaling Technology). Detection was accomplished using enhanced chemiluminescence Western blotting (ECL, GE Healthcare, Piscataway, NJ, USA). Relative band intensity was measured densitometrically by ImageJ software with $\beta$-actin as an internal control.

\section{Endocytosis of albumin by cultured PECs}

To evaluate the cellular uptake and internalization of albumin, we treated the primary PECs with Alexa Fluor 488-labeled bovine serum albumin (AF488-BSA). After 6 days, PECs grown in glass-bottomed 35-mm tissue culture dishes were washed and incubated with fresh 
culture medium containing AF488-BSA ( $100 \mu \mathrm{g} / \mathrm{ml})$ for 2 hours. The cells were then washed for three times with PBS, fixed with $4 \%$ formaldehyde, and counterstained for DAPI. Images were captured using a Leica confocal microscope (Wetzlar, Germany).

\section{Statistical analysis}

Data are expressed as mean \pm SEM. Student's $t$ test was used for comparison between two groups. Comparisons among multiple groups were performed by one-way ANOVA followed by Newman-Keuls post hoc test. Statistical significance was set at $P<0.05$.

\section{Results}

\section{CD44 gene expression was up-regulated in the glomeruli of diabetic rats}

Compared to age-matched ZL controls, ZD rats demonstrated a progressive increase in urinary albumin excretion at age 7-20 weeks (Figure 1A). Blood glucose in ZD rats increased dramatically at 12 weeks and remained at high levels afterwards (Figure 1B). Real-time PCR analysis was performed to compare CD44 gene expression in the glomeruli of ZL and ZD rats. As shown in Figure 1C, glomerular CD44 mRNA in ZD rats was lower at 7 weeks but significantly increased at 12 and 20 weeks compared to age-matched ZL rats.

\section{CD44 induction was associated with increased albumin reabsorption by activated PECs in the diabetic kidneys}

Next, we confirmed an increase in parietal expression of CD44 protein in damaged glomeruli of ZD rats by double immunostaining rat kidney sections for CD44 and claudin-1, a specific marker of PECs. CD44 was expressed at low levels in normal rat glomeruli but became upregulated in activated PECs of damaged glomeruli. As depicted in Figure 2A, occasional CD44 staining was co-localized with claudin-1 in PECs situated within the parietal layer of Bowman's capsule in normal 20-week-old ZL rats. In the diabetic glomeruli, substantial CD44 and claudin-1 positive cells were also observed in Bowman's space and glomerular tufts (Figure 2B - diabetic).

We have recently reported an increase in albumin endocytosis by proximal tubules in ZD rats (Chen et al, 2017). Here, we further show a substantial increase in albumin uptake by activated PECs in the diabetic rat kidneys. Normally, albumin was restrained in the capillary of glomeruli. However, increased albumin accumulation was observed in dilated Bowman's space of ZD glomeruli (Figure 2B). Abundant albumin signal was also shown in the apical membrane and intracellular vesicles of hypertrophic PECs, indicating an increase of albumin endocytosis by PECs in response to an elevation of albumin filtration. Moreover, intense CD44 staining was detected in PECs overloaded with albumin, suggesting a close correlation between albumin exposure and CD44 induction.

\section{Losartan attenuated albuminuria and mitigated CD44 expression in the diabetic kidneys}

Angiotensin II antagonist losartan has been proven to reduce proteinuria in diabetics and nondiabetics. Therefore, we next studied the effect of anti-proteinuric treatment with losartan on CD44 expression in the diabetic rats. As expected, chronic administration of losartan for 8 weeks had no effect on blood glucose (Figure 3A) but significantly decreased 
urinary albumin in ZD rats (Figure 3B). In agreement with an increase in CD44 staining in the diabetic glomeruli, Western blot analysis confirmed a significant elevation of CD44 protein in kidney cortex of ZD rats (Figure 3C-D). In concurrence with an attenuation of albuminuria, diabetes-associated CD44 upregulation was greatly suppressed by losartan.

\section{Albumin stimulated CD44 and claudin-1 protein expression in primary cultured rat PECs}

To further evaluate the effect of albumin on CD44 expression, primary culture of PECs was prepared using capsulated glomeruli isolated from normal rat kidneys. After 6-7 days, glomerular PECs predominantly showed a spindle-shaped or squamous (polygonal) morphology along with expression of CD44 at the plasma membrane (Figure 4A) (Kabgani et al, 2012). To directly visualize the endocytic uptake of albumin by primary PECs, the cells were incubated with AF488-BSA. Representative confocal images show AF488-BSA bright green staining in vesicular punctuate structures after 2-hour incubation (Figure 4B).

We next determined whether albumin overload of PECs could stimulate CD44 expression by Western blot analysis. Incubation of PECs with RSA $(0.25-1 \mathrm{mg} / \mathrm{ml})$ resulted in a dosedependent increase in CD44 protein, which was accompanied by an upregulation of PEC marker claudin-1 following RSA treatment for 24 (Figure 4C-E) or 72 hours (Figure 4C'E').

\section{Albumin-induced CD44 and claudin-1 in PECs were dependent on ERK1/2 activation}

We next sought to understand the mechanism for albumin-induced CD44 expression by PECs. A recent study by Roeder et al. has shown that de novo expression of CD44 in mouse PECs following podocyte injury is mediated in part by ERK1/2 activation (Roeder et al, 2017). This finding led us to ask whether the ERK1/2 signaling pathway is also involved in albumin-induced CD44 expression in PECs. In line with our previous findings (Zhang et al, 2015), exposure of PECs to $0.5 \mathrm{mg} / \mathrm{ml}$ RSA for 3 hours resulted in an activation of ERK1/2, whereas p38 MAP kinase and Akt activation was not activated (Figure 5). Inhibition of ERK1/2 phosphorylation using U0126 significantly blocked albumin-induced CD44 and claudin-1 expression in primary rat PECs (Figure 6A). In contrast, albumin-induced CD44 upregulation was not affected by the PI3K inhibitor LY294002 (Figure 6B).

\section{Increased megalin expression is involved in albumin-induced CD44 in PECs}

It is well known that the multiligand receptor megalin plays an essential role in the reabsorption of filtered albumin by the proximal tubules. A recent study also suggests that the in vivo endocytosis of albumin by podocytes occurs in a megalin-dependent manner (Schiessl et al, 2016). Therefore, we examined the possible role of megalin in albumininduced CD44 expression in PECs. In the current study, immunofluorescence staining of rat kidney sections confirmed megalin expression in podocytes and proximal tubule cells (Figure 7). Interestingly, intense megalin staining was also detected on the apical membrane of hypertrophic PECs (Figure 7A-B), whereas only weak megalin signal was present in normal flat PECs. Moreover, those hypertrophic megalin-positive PECs often stained positive for CD44 on the basolateral membrane. We also observed a decrease of megalin protein in CD44-positive visceral epithelial cells in the damaged glomeruli of ZD rats. As 
depicted in Figure 7C, abundant CD44 staining was seen in dilated proximal tubule epithelial cells in ZD kidneys.

Our in vivo results showed a close relationship between megalin expression and CD44 induction in activated PECs. We then examined the function role of megalin in albumininduced CD44 expression in cultured rat PECs. As shown in Figure 8, albumin stimulation resulted in an upregulation of megalin and claudin-1, which was greatly attenuated by knockdown of megalin using siRNA interference. Both CD44 and claudin-1 protein levels were significantly lowered in PECs transfected with megalin siRNA compared to that in scramble siRNA-treated cells.

\section{Effects of high glucose and TGF- $\beta 1$ on CD44 and claudin-1 expression in cultured rat PECs}

In diabetes mellitus, increased TGF- $\beta$ expression in the kidney mediates the renal actions of high ambient glucose to stimulate protein synthesis and promote cellular hypertrophy. Thus, primary PECs were also treated with high glucose and recombinant TGF- $\beta 1$ to mimic the diabetic condition. As depicted in Figure 9, CD44 protein levels were not significantly changed when the cells were exposed to high glucose or mannitol for 24 (Figure 9A-B) or 72 hours (Figure 9A'-B'), whereas an upregulation of claudin-1 was observed in PECs treated with high glucose or mannitol for 24 hours (Figure 9C). Incubation of PECs with TGF- $\beta 1$ ( $4 \mathrm{ng} / \mathrm{ml})$ resulted in a slight increase in CD44 protein at 24 hours (Figure 9A-B). In contrast, a significant decrease in claudin-1 protein in PECs was detected following TGF$\beta 1$ treatment for 24 (Figure 9C) or 72 hours (Figure 9C').

\section{Discussion}

Studies in animals and humans have shown that CD44 is a specific marker of activated PECs that invade the glomerular tuft during scarring glomerular diseases (Eymael et al, 2017;Froes et al, 2017;Kim et al, 2016;Okamoto et al, 2013;Roeder et al, 2017). Our main research questions were whether CD44 expression could be regulated by urinary albumin in proteinuric kidney disease, and, if so, whether albumin-induced CD44 was dependent on activation of the ERK1/2 signaling pathway and involvement of the endocytic receptor megalin. Our in vivo results indicated that an increase in glomerular expression of CD44 was associated with albumin overload and PEC activation in glomerular lesions and that losartan treatment attenuated albuminuria and reduced CD44 protein in the diabetic rat kidneys. Our in vitro cell culture study further revealed a stimulatory effect of albumin on CD44 and claudin-1 protein expression in primary cultured rat PECs. Furthermore, the albumin-induced increase in CD44 and claudin-1 was significantly reduced by inhibition of the ERK1/2 signaling pathway or knockdown of megalin.

Previous studies have shown that an increase in CD44 is associated with experimental and clinical sclerotic glomerular disease (Eymael et al, 2017;Fatima et al, 2012; Froes et al, 2017;Kim et al, 2016;Okamoto et al, 2013;Roeder et al, 2017; Yamazaki et al, 2016). Presence of CD44 staining in PECs was significantly associated with a decline in baseline eGFR of 50\% or more, and renal survival was significantly reduced in PEC CD44-positive patients (Froes et al, 2017). Our results are in agreement with these studies and showed a progressive increase in albuminuria and glomerular CD44 gene expression in ZD rats. Our 
immunofluorescence data also confirmed increased CD44 in claudin-1-positive glomerular epithelial cells in damaged glomeruli. Detection of CD44+ PECs in Bowman's space and glomerular tuft in more severely damaged glomeruli is consistent with previous reports that migration increases in PECs expressing CD44 (Eymael et al, 2017; Roeder et al, 2017).

CD44 expression by activated PECs was increased in association with albuminuria and disease progression in ZD rats. Increased albumin filtration resulted in an accumulation of albumin in Bowman's space and subsequent endocytosis by neighboring PECs. Intense CD44 signal in hypertrophic PECs with albumin-containing intracellular vesicles supports a close correlation between albumin overload and CD44 induction in diabetic glomerular disease. This is also in agreement with data from Yang et al. (Yang et al, 2011), indicating that inflammatory gene expression is correlated with albuminuria and that CD44 increased in albumin-overloaded proximal tubules in OVE26 diabetic mice. In the current study, we also found that the increase in renal CD44 was significantly attenuated in ZD kidneys following losartan treatment. Since losartan reduced albuminuria but had no effect on blood glucose, the downregulation of CD44 protein in treated-ZD rats is probably due to a reduction of albumin filtration. Thus, our in vivo study suggested, but did not prove, that albumin overload could activate PECs, leading to an upregulation of CD44 expression in diabetic glomerular disease.

We next performed in vitro cell culture study to test the hypothesis that albumin overload could stimulate CD44 expression in PECs. Immunostaining and Western blot analyses confirmed the expression of CD44 and claudin-1 in primary cultured rat PECs. Both CD44 and claudin-1 protein levels were increased in cultured PECs upon albumin stimulation. Roeder et al. have reported that CD44 expression is regulated by the ERK signaling pathway, and increased CD44 protein leads to a prosclerotic and migratory PEC phenotype (Roeder et al, 2017). Thus, we next examined the involvement of MAP kinase activation in albumin-induced CD44. The phosphorylation of ERK1/2 but not p38 MAPK was significantly increased when the primary PECs were exposed to albumin. An attenuation of albumin-induced CD44 in the presence of ERK1/2 inhibitor U0126 supports that albumin may induce CD44 expression in PECs through activation of the ERK signaling pathway. Although our in vitro findings support that albumin may induce CD44 expression in PECs through the ERK signaling pathway, further in vivo studies are required to examine the mediators and signaling pathways involved in albumin overload-related PEC activation and CD44 expression in diabetic glomerular disease.

In the current study, endocytosis of albumin by PECs was confirmed by accumulation of AF488-conjugated albumin in intracellular vesicles. It is well known that the endocytic receptor megalin plays an essential role in the reabsorption of filtered albumin by the proximal tubule epithelial cells. In addition, the expression of megalin and cubilin has been localized in rat and human podocytes (Kerjaschki and Farquhar, 1983;Prabakaran et al, 2011;Prabakaran et al, 2012;Schiessl et al, 2016). A co-localization of albumin with megalin within the podocytes suggests that the in vivo endocytosis of albumin by podocytes occurs in a megalin-dependent manner. Our kidney immunostaining data not only confirmed the expression of megalin in rat podocytes but also revealed increased megalin in activated PECs. Additionally, ZD rats demonstrated intensive apical staining for megalin in 
association with high CD44 on the basolateral membrane in hypertrophic PECs lining Bowman's capsule. Of note, megalin is low or absent in CD44-positive PECs in the glomerular tuft area. This decrease in megalin expression may be due to a loss of epithelial cell polarity once PEC migration occurs.

Our in vivo data also suggest that albumin overload may lead to expression alteration of epithelial megalin. In fact, Sun et al. have confirmed a mechanistic link between the tubular plasma protein and levels of megalin and cubilin in a proteinuric zebrafish model (Sun et al, 2017). They observed a dose-dependent increase in plasma protein uptake due to glomerular damage, and this in turn resulted in an increased expression of megalin and cubilin. In this study, we provided evidence that albumin overload upregulates megalin expression in cultured PECs. Moreover, we show that albumin-induced CD44 expression by PECs is partially mediated by megalin since megalin deficiency resulted in a suppression of CD44 following albumin stimulation.

In the current study, incubation of PECs with high glucose for 24 or 72 hours was found to have no impact on CD44 protein, suggesting that high glucose may play a minor regulatory role in CD44 expression. Addition of $4 \mathrm{ng} / \mathrm{ml}$ recombinant TGF- $\beta 1$ resulted in a slight increase in CD44 protein in PECs at 24 hours. This is in line with previous findings in renal tubular cells that $5 \mathrm{ng} / \mathrm{ml} \mathrm{TGF-} \beta 1$ increased CD44, peaking at 12 hours and then declining but remaining above controls by 48 hours. Our data also support a stimulatory effect of hyperosmolarity on claudin-1 expression since its protein levels were significantly increased in both high glucose and mannitol-treated PECs. In contrast, TGF- $\beta 1$ downregulates claudin-1 and induces fibrotic protein expression (data not shown) in PECs.

CD44 is not only a biomarker of PEC activation but also known to be involved in many cellular processes, including cell migration and proliferation. De novo expression of CD44 in PECs following podocyte injury increases PEC matrix production and migration (Roeder et al, 2017). Studies performed in CD44-deficient mice further demonstrate that CD44 is required for the pathogenesis of experimental crescentic glomerulonephritis and collapsing focal segmental glomerulosclerosis (Eymael et al, 2017). Our in vivo results also suggest that albumin overload-associated CD44 expression by PECs may lead to progressive loss of cell junction and gain of migratory phenotype in proteinuric kidney disease. Experiments are currently underway to determine whether antibody neutralization or siRNA knockdown of CD44 would prevent albumin-induced PEC proliferation and migration. Moreover, CD44 has many splice variants, which each specific binding partners, thereby linking to various signaling pathways. Therefore, additional studies are required to elucidate the exact molecular mechanisms underlying proliferation and migration of CD44-positive PECs during sclerotic lesion formation in diabetic glomerular disease.

In summary, we found that CD44 expression in PECs was increased in association with albuminuria and nephropathy progression in diabetic rats. An increase in CD44 expression was prevented by antiproteinuric treatment with losartan in the ZD rats. Albumin overloadinduced claudin-1 and CD44 expression in cultured PECs was dependent on the activation of the ERK signaling pathway and megalin expression. Our results indicate that inhibition of 
albumin overload and CD44 expression may represent a major opportunity for the prevention and treatment of proteinuric kidney diseases.

\section{Acknowledgements}

This work was supported by the NIH SC1DK112151, NIH/NCRR/RCMI 8G12MD007602 and 8U54MD007588.

\section{Literature Cited}

Abbate M, Zoja C, Remuzzi G (2006). How does proteinuria cause progressive renal damage? J Am Soc Nephrol 17:2974-2984. [PubMed: 17035611]

Amsellem S, Gburek J, Hamard G, Nielsen R, Willnow TE, Devuyst O, Nexo E, Verroust PJ, Christensen EI, Kozyraki R (2010). Cubilin is essential for albumin reabsorption in the renal proximal tubule. J Am Soc Nephrol 21:1859-1867. [PubMed: 20798259]

Chatelet F, Brianti E, Ronco P, Roland J, Verroust P (1986). Ultrastructural localization by monoclonal antibodies of brush border antigens expressed by glomeruli. I. Renal distribution. Am J Pathol 122:500-511. [PubMed: 3953773]

Chen X, Cobbs A, George J, Chima A, Tuyishime F, Zhao X (2017). Endocytosis of Albumin Induces Matrix Metalloproteinase-9 by Activating the ERK Signaling Pathway in Renal Tubule Epithelial Cells. Int J Mol Sci 18.

Dinneen SF, Gerstein HC (1997). The association of microalbuminuria and mortality in non-insulindependent diabetes mellitus. A systematic overview of the literature. Arch Intern Med 157:14131418. [PubMed: 9224218]

Diwakar R, Pearson AL, Colville-Nash P, Brunskill NJ, Dockrell ME (2007). The role played by endocytosis in albumin-induced secretion of TGF-beta1 by proximal tubular epithelial cells. Am J Physiol Renal Physiol 292:F1464-F1470. [PubMed: 17213467]

Eymael J, Sharma S, Loeven MA, Wetzels JF, Mooren F, Florquin S, Deegens JK, Willemsen BK, Sharma V, van Kuppevelt TH, Bakker MA, Ostendorf T, Moeller MJ, Dijkman HB, Smeets B, van d $\mathrm{V}$ (2017). CD44 is required for the pathogenesis of experimental crescentic glomerulonephritis and collapsing focal segmental glomerulosclerosis. Kidney Int.

Fatima H, Moeller MJ, Smeets B, Yang HC, D’Agati VD, Alpers CE, Fogo AB (2012). Parietal epithelial cell activation marker in early recurrence of FSGS in the transplant. Clin J Am Soc Nephrol 7:1852-1858. [PubMed: 22917699]

Froes BP, de Almeida AS, Bambirra EA, Oliveira EA, Simoes E Silva AC, Pinheiro SVB (2017). Is CD44 in glomerular parietal epithelial cells a pathological marker of renal function deterioration in primary focal segmental glomerulosclerosis? Pediatr Nephrol 32:2165-2169. [PubMed: 28799058]

Kabgani N, Grigoleit T, Schulte K, Sechi A, Sauer-Lehnen S, Tag C, Boor P, Kuppe C, Warsow G, Schordan S, Mostertz J, Chilukoti RK, Homuth G, Endlich N, Tacke F, Weiskirchen R, Fuellen G, Endlich K, Floege J, Smeets B, Moeller MJ (2012). Primary cultures of glomerular parietal epithelial cells or podocytes with proven origin. PLoS One 7:e34907. [PubMed: 22529955]

Kerjaschki D, Farquhar MG (1983). Immunocytochemical localization of the Heymann nephritis antigen (GP330) in glomerular epithelial cells of normal Lewis rats. J Exp Med 157:667-686. [PubMed: 6337231]

Kim S, Kim YH, Choi KH, Jeong HJ (2016). Glomerular epithelial CD44 expression and segmental sclerosis in IgA nephropathy. Clin Exp Nephrol 20:871-877. [PubMed: 26711244]

Lim BJ, Yang JW, Do WS, Fogo AB (2016). Pathogenesis of Focal Segmental Glomerulosclerosis. J Pathol Transl Med 50:405-410. [PubMed: 27744657]

Lin JS, Susztak K (2016). Podocytes: the Weakest Link in Diabetic Kidney Disease? Curr Diab Rep 16:45. [PubMed: 27053072]

Marhaba R, Zoller M (2004). CD44 in cancer progression: adhesion, migration and growth regulation. J Mol Histol 35:211-231. [PubMed: 15339042]

Mariappan MM, D'Silva K, Lee MJ, Sataranatarajan K, Barnes JL, Choudhury GG, Kasinath BS (2011). Ribosomal biogenesis induction by high glucose requires activation of upstream binding 
factor in kidney glomerular epithelial cells. Am J Physiol Renal Physiol 300:F219-F230. [PubMed: 20943765]

Nangaku M (2004). Mechanisms of tubulointerstitial injury in the kidney: final common pathways to end-stage renal failure. Intern Med 43:9-17. [PubMed: 14964574]

Okamoto T, Sasaki S, Yamazaki T, Sato Y, Ito H, Ariga T (2013). Prevalence of CD44-positive glomerular parietal epithelial cells reflects podocyte injury in adriamycin nephropathy. Nephron Exp Nephrol 124:11-18. [PubMed: 24401840]

Prabakaran T, Christensen EI, Nielsen R, Verroust PJ (2012). Cubilin is expressed in rat and human glomerular podocytes. Nephrol Dial Transplant 27:3156-3159. [PubMed: 22337902]

Prabakaran T, Nielsen R, Larsen JV, Sorensen SS, Feldt-Rasmussen U, Saleem MA, Petersen CM, Verroust PJ, Christensen EI (2011). Receptor-mediated endocytosis of alpha-galactosidase A in human podocytes in Fabry disease. PLoS One 6:e25065. [PubMed: 21949853]

Roeder SS, Barnes TJ, Lee JS, Kato I, Eng DG, Kaverina NV, Sunseri MW, Daniel C, Amann K, Pippin JW, Shankland SJ (2017). Activated ERK1/2 increases CD44 in glomerular parietal epithelial cells leading to matrix expansion. Kidney Int 91:896-913. [PubMed: 27998643]

Schiessl IM, Hammer A, Kattler V, Gess B, Theilig F, Witzgall R, Castrop H (2016). Intravital Imaging Reveals Angiotensin II-Induced Transcytosis of Albumin by Podocytes. J Am Soc Nephrol 27:731-744. [PubMed: 26116357]

Sun J, Hultenby K, Axelsson J, Nordstrom J, He B, Wernerson A, Lindstrom K (2017). Proximal Tubular Expression Patterns of Megalin and Cubilin in Proteinuric Nephropathies. Kidney Int Rep 2:721-732. [PubMed: 29142988]

Takaya K, Koya D, Isono M, Sugimoto T, Sugaya T, Kashiwagi A, Haneda M (2003). Involvement of ERK pathway in albumin-induced MCP-1 expression in mouse proximal tubular cells. Am J Physiol Renal Physiol 284:F1037-F1045. [PubMed: 12517735]

Wang Y, Rangan GK, Tay YC, Wang Y, Harris DC (1999). Induction of monocyte chemoattractant protein-1 by albumin is mediated by nuclear factor kappaB in proximal tubule cells. J Am Soc Nephrol 10:1204-1213. [PubMed: 10361858]

Yamazaki T, Sasaki S, Okamoto T, Sato Y, Hayashi A, Ariga T (2016). Up-Regulation of CD74 Expression in Parietal Epithelial Cells in a Mouse Model of Focal Segmental Glomerulosclerosis. Nephron 134:238-252. [PubMed: 27463800]

Yang L, Brozovic S, Xu J, Long Y, Kralik PM, Waigel S, Zacharias W, Zheng S, Epstein PN (2011). Inflammatory gene expression in OVE26 diabetic kidney during the development of nephropathy. Nephron Exp Nephrol 119:e8-20. [PubMed: 21606656]

Yard BA, Chorianopoulos E, Herr D, van der Woude FJ (2001). Regulation of endothelin-1 and transforming growth factor-beta1 production in cultured proximal tubular cells by albumin and heparan sulphate glycosaminoglycans. Nephrol Dial Transplant 16:1769-1775. [PubMed: 11522857]

Zhang Y, George J, Li Y, Olufade R, Zhao X (2015). Matrix metalloproteinase-9 expression is enhanced in renal parietal epithelial cells of zucker diabetic Fatty rats and is induced by albumin in in vitro primary parietal cell culture. PLoS One 10:e0123276. [PubMed: 25849723]

Zhao X, Zhang Y, Li L, Mann D, Imig JD, Emmett N, Gibbons G, Jin LM (2011). Glomerular expression of kidney injury molecule-1 and podocytopenia in diabetic glomerulopathy. Am $\mathbf{J}$ Nephrol 34:268-280. [PubMed: 21822010]

Zoja C, Donadelli R, Colleoni S, Figliuzzi M, Bonazzola S, Morigi M, Remuzzi G (1998). Protein overload stimulates RANTES production by proximal tubular cells depending on NF-kappa B activation. Kidney Int 53:1608-1615. [PubMed: 9607191] 

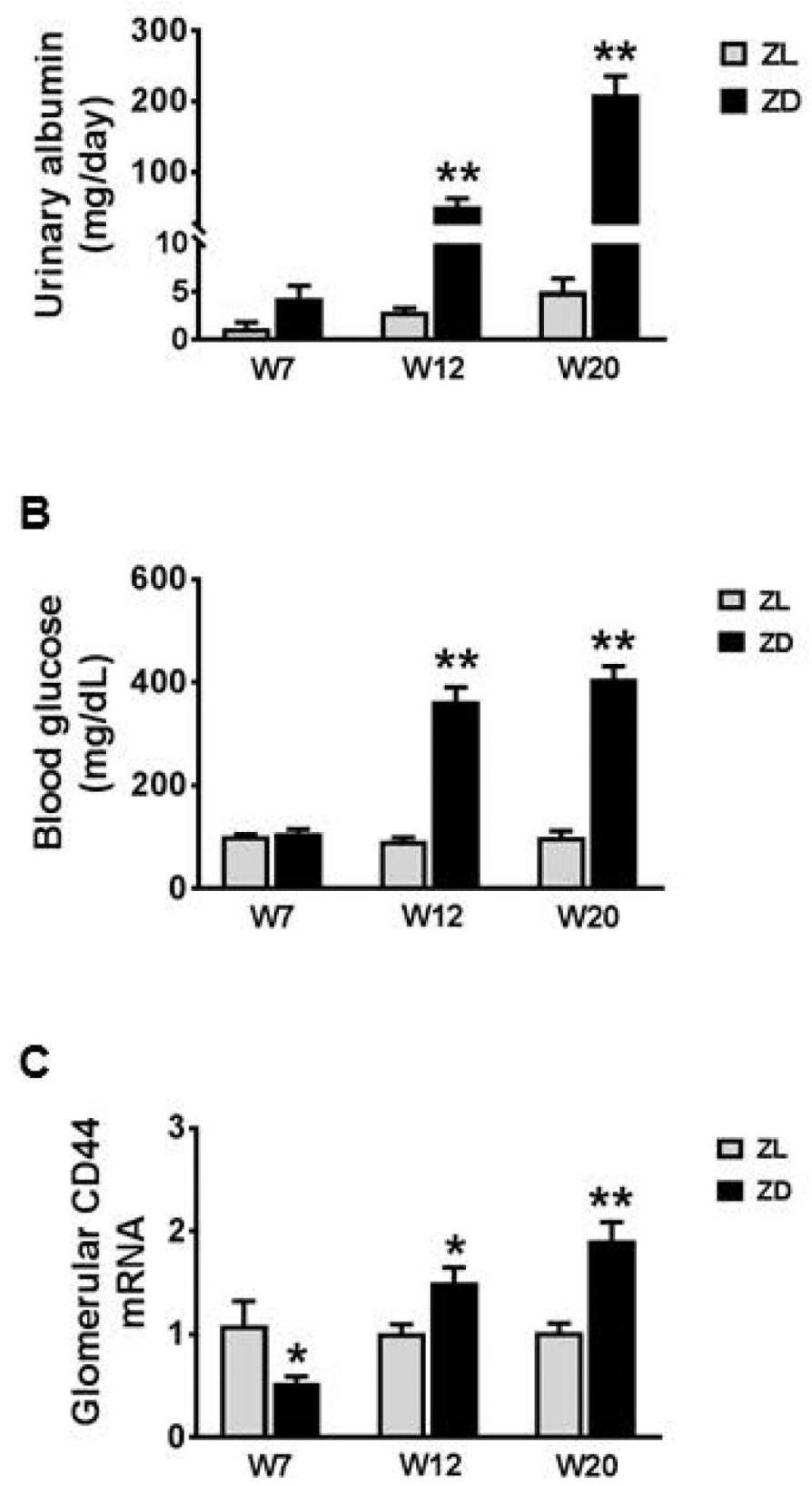

Figure 1. CD44 gene expression was upregulated in the glomeruli of diabetic rats.

(A) Zucker diabetic (ZD) rats demonstrated an age-dependent increase in urinary albumin excretion compared to age-matched Zucker lean (ZL) controls. (B) A substantial increase in blood glucose was seen in 12-week-old ZD rats and its level remained higher thereafter. (C) Real-time PCR analysis showed a progressive increase in CD44 gene expression in the glomeruli of ZD rats. Glomerular CD44 mRNA level was initially lower in 7-week-old ZD rats. However, CD44 transcript was significantly increased in 12- and 20-week-old ZD rats compared to age-matched ZL controls. Values are mean \pm SEM. $\mathrm{n}=4-6$ rats; $* P<0.05$, $* * P<0.01$ vs. age-matched ZL control group. 

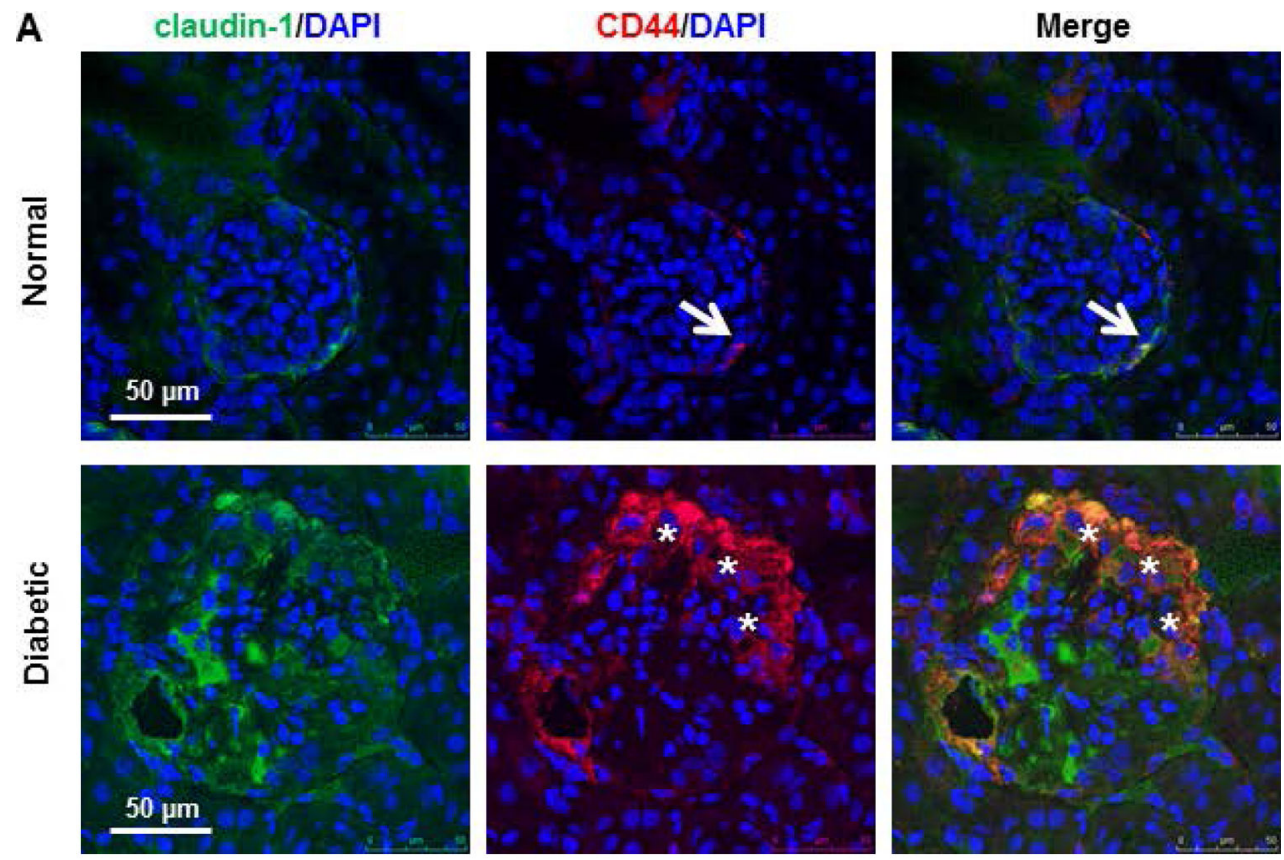

B
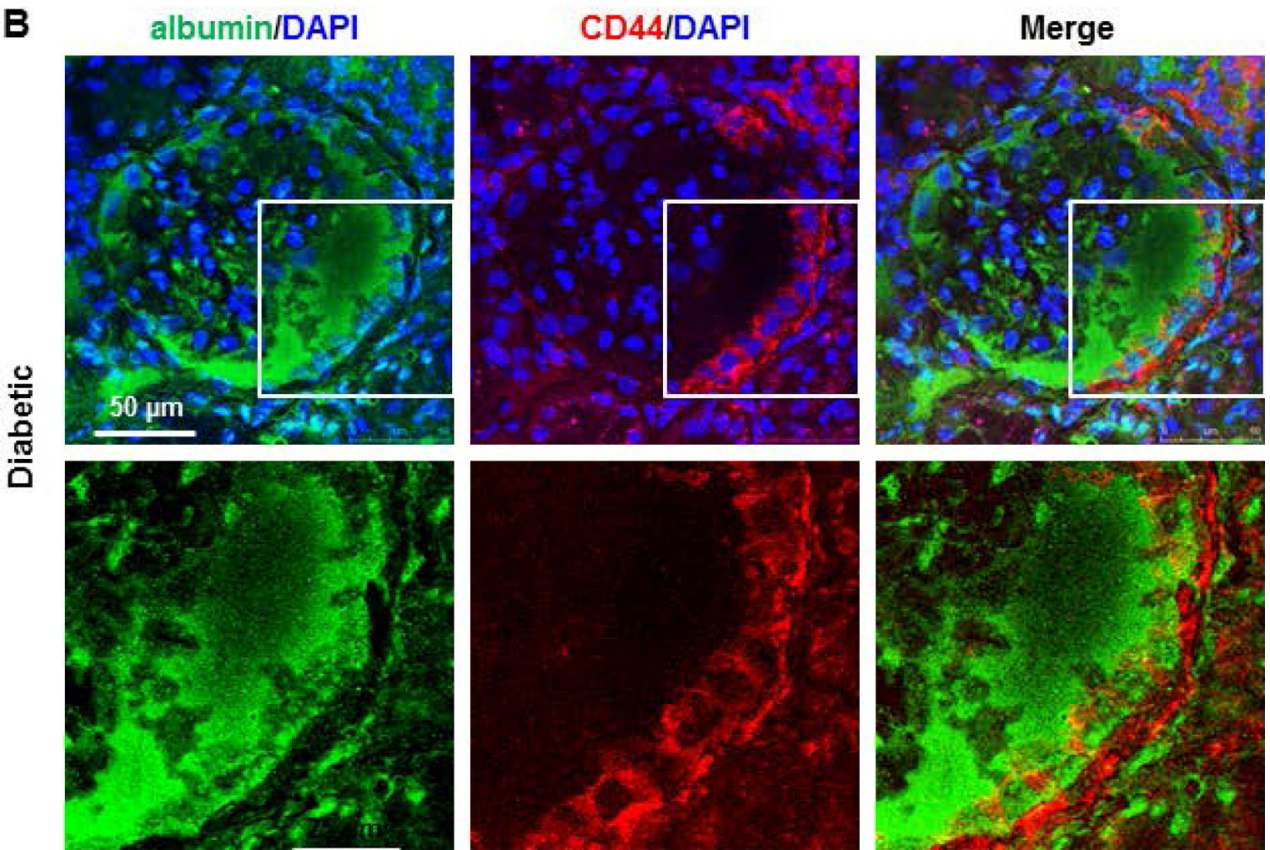

Figure 2. CD44 staining was increased in association with albumin overload in PECs of ZD rats. (A) Dual labelling of kidney sections for PEC marker claudin-1 (green) and CD44 (red). The nuclei were counterstained with DAPI (blue). In normal glomeruli, occasional CD44 staining (white arrow) was revealed in claudin-1-positive PECs within the Bowman's capsule. In diabetic rats, increased CD44 positive cells were also observed in Bowman's space and glomerular tuft (white star) of damaged glomeruli (Diabetic). (B) In diabetic glomeruli, albumin (green) was accumulated in dilated Bowman's space. Consequently, 
albumin uptake by neighboring PECs was increased. Intense CD44 red staining was present in albumin overload PECs, which exhibit proliferative and hypertrophic phenotype. 


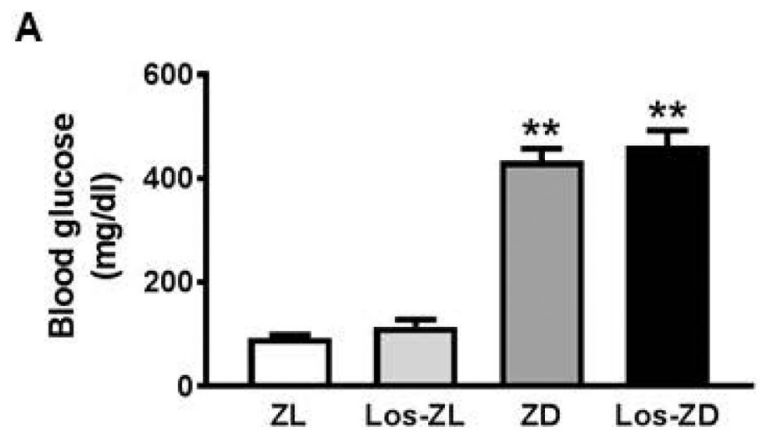

B
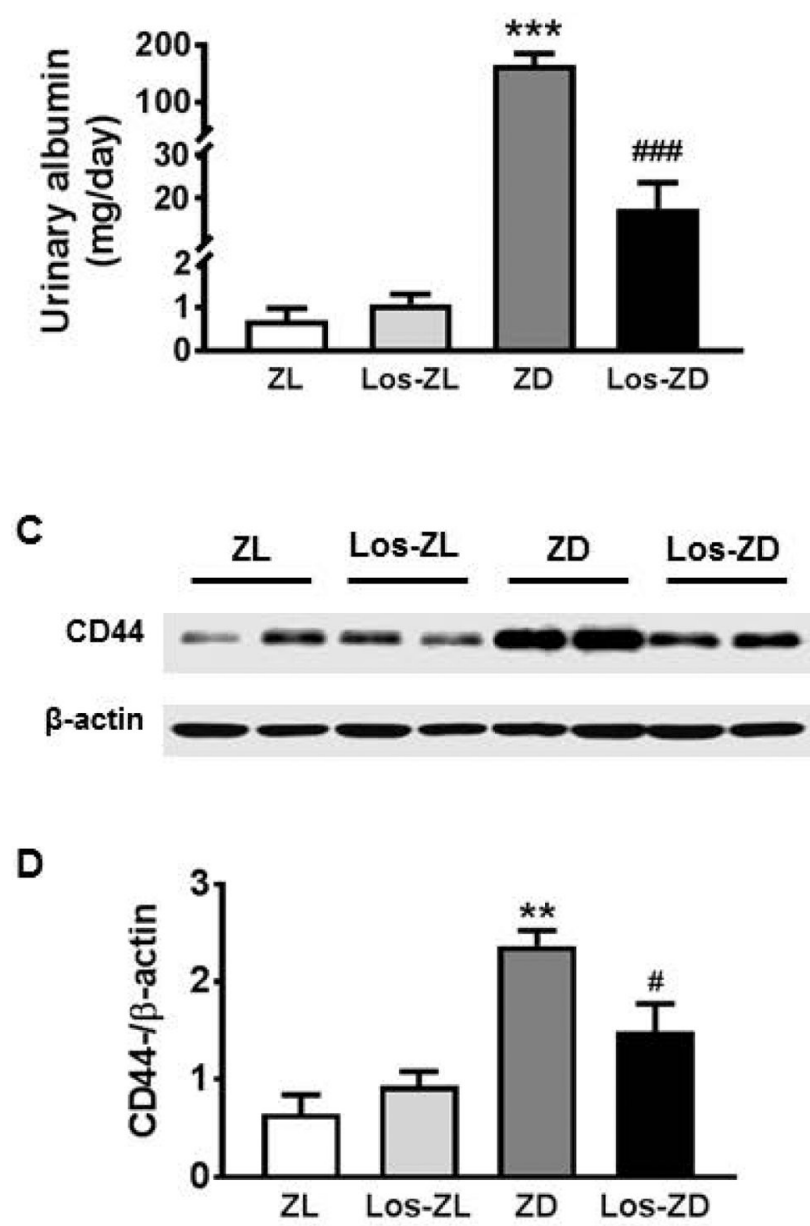

Figure 3. Effect of losartan on CD44 protein expression in the kidney cortex of Zucker rats. (A-B) Losartan treatment for 8 weeks had no effect on blood glucose (A) but significantly lowered urinary albumin levels in ZD rats (B). (C-D) Western blot analysis confirmed an increase in CD44 protein expression in ZD kidneys, which was significantly attenuated by losartan (Los). Representative immunoblots were shown in (C), and the statistics (mean \pm SEM, $n=4-6$ animals/group) of the optical density ratio normalized to the density of $\beta$ actin were shown in (D). ${ }^{*} * P<0.01, * * * P<0.001$ compared with ZL control; ${ }^{\#} P<0.05$, \#\#\# $P<0.001$ compared to untreated ZD rats (Los-ZD vs ZD). 
A

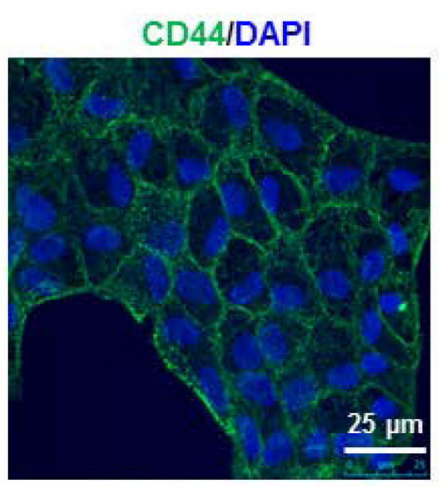

C

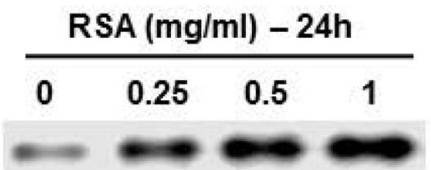

CD44

Claudin1

$\beta$-actin

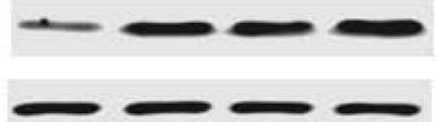

D

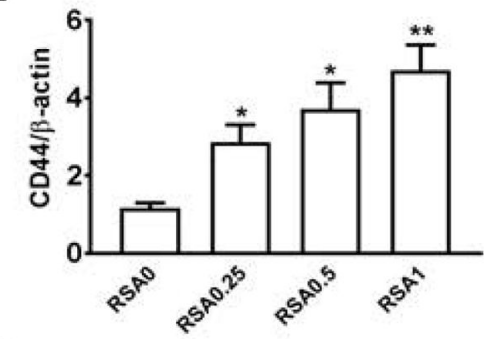

E

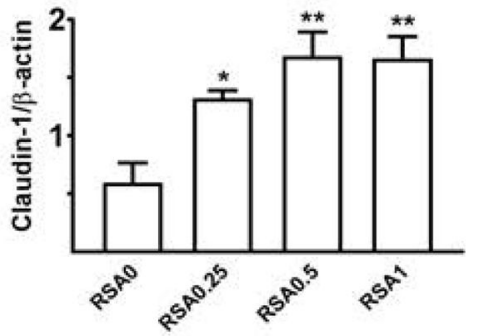

B

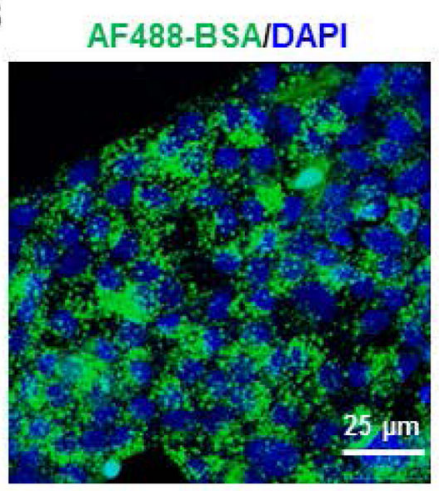

C'

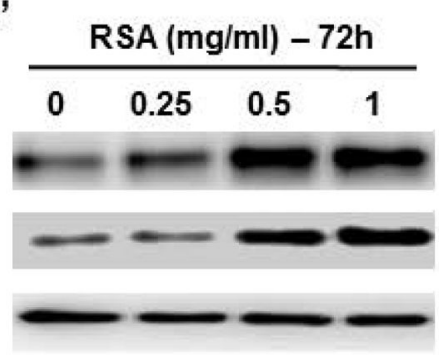

D'

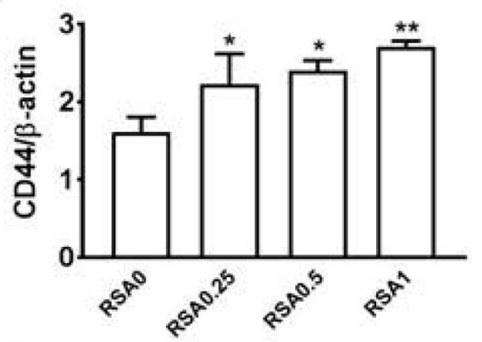

E'

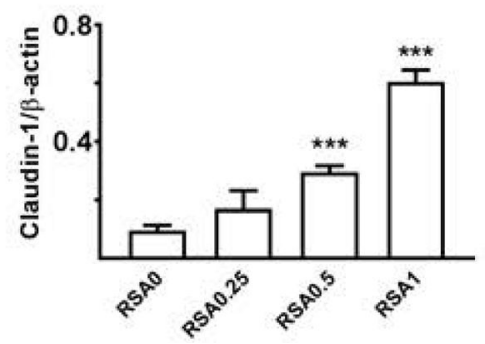

Figure 4. Albumin increased CD44 and claudin-1 protein in primary culture of rat PECs.

(A) Representative confocal image shows CD44 staining (green) on the cell surface of PECs. (B) Albumin uptake was visualized in intracellular vesicles after the cells were incubated with $100 \mu \mathrm{g} / \mathrm{ml}$ Alexa Fluor 488-labeled bovine serum albumin (AF488-BSA, bright green) at $37^{\circ} \mathrm{C}$ for 2 hours. (C-E') Rat serum albumin (RSA, $0.25-1 \mathrm{mg} / \mathrm{ml}$ ) administration for 24 (C-E) or 72 (C'-E') hours resulted in a dose-dependent increase in CD44 and claudin-1 proteins in primary cultured PECs. Quantitative data (mean \pm SEM) in D-E and D'-E' are 
summarized from $\mathrm{n}=3-5$ separate experiments. $* P<0.05$, $* * P<0.01$, $* * * P<0.01$ vs. untreated control group. 

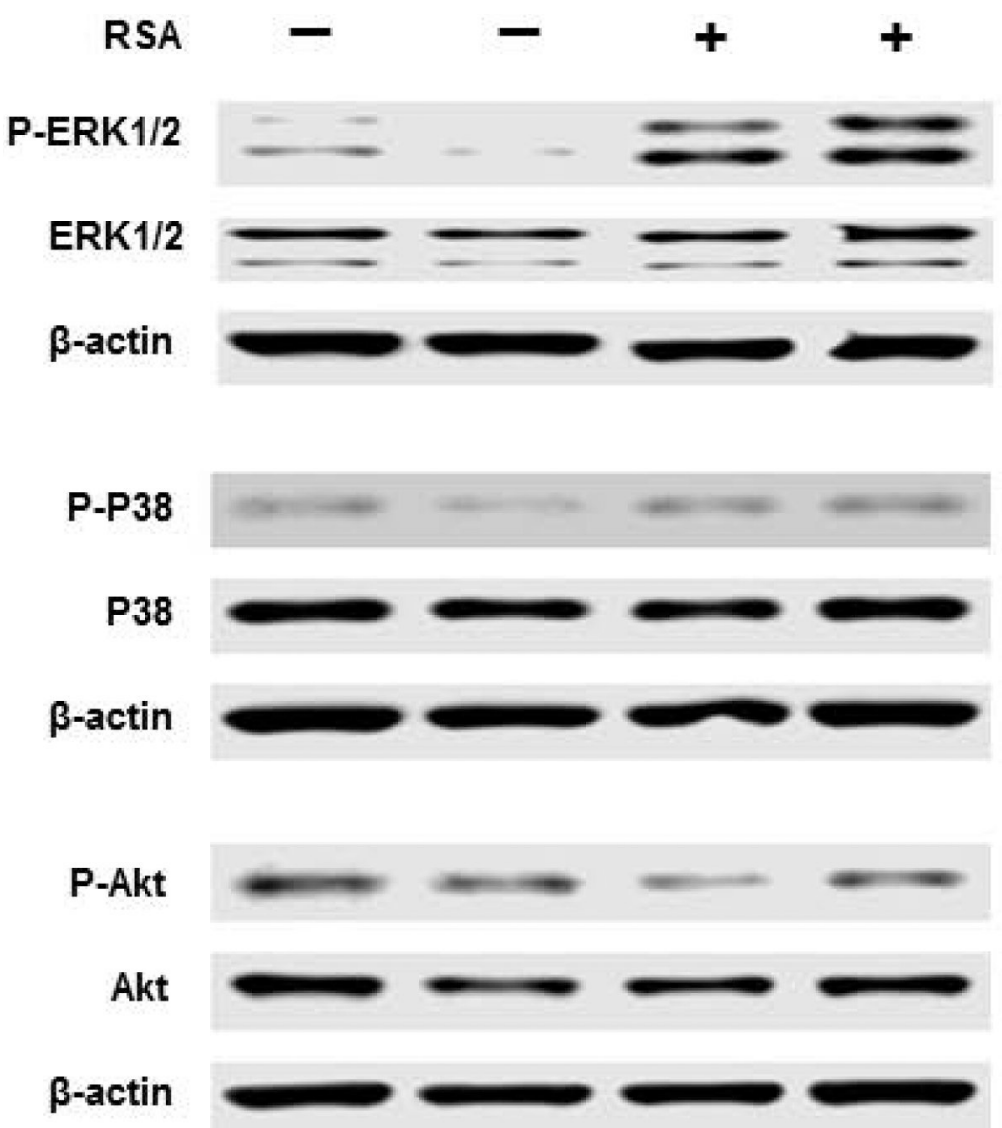

Figure 5. ERK1/2 MAP kinase was activated by albumin in PECs.

Representative Western blots show protein levels of phosphor-and total ERK1/2, P38 and Akt in PECs in the absence or presence of RSA $(0.5 \mathrm{mg} / \mathrm{ml})$ for 3 hours. 

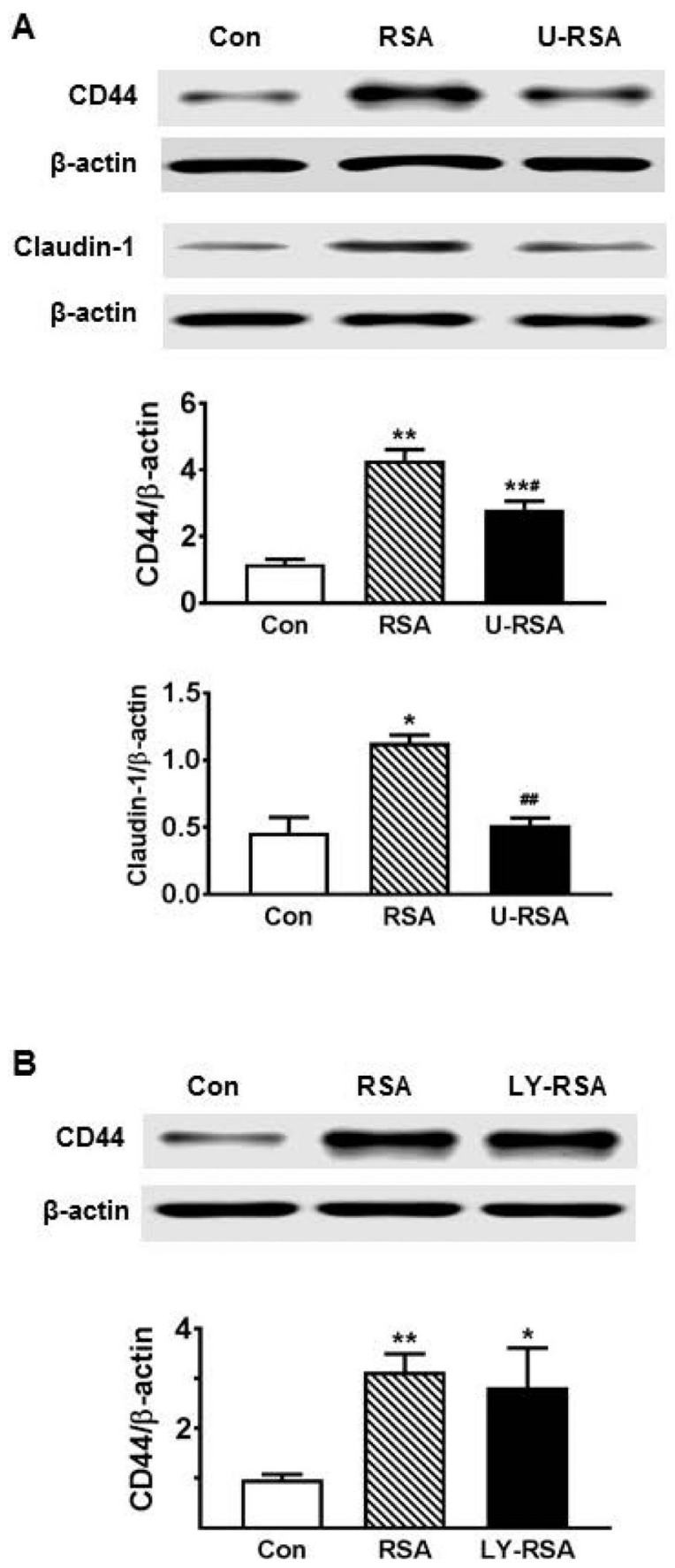

Figure 6. Inhibition of ERK1/2 phosphorylation suppressed albumin-induced CD44 and claudin-1 in PECs.

(A) U0126 (U-RSA), a selective ERK1/2 inhibitor, significantly reduced CD44 and claudin-1 proteins in PECs treated with RSA $(0.5 \mathrm{mg} / \mathrm{ml})$ for 24 hours. (B) The PI3K inhibitor LY294002 (LY-RSA) had no effect on albumin-induced CD44 expression. Quantitative data (mean \pm SEM) in $\mathbf{A}$ and $\mathbf{B}$ are summarized from $n=3-5$ separate experiments. ${ }^{*} P<0.05$, $* * P<0.01$ vs. unstimulated normal control; ${ }^{\#} P<0.05,{ }^{\#} P<0.01$ vs. vehicle-treated albumin-stimulated cells. 
Megalin/DAPI

A

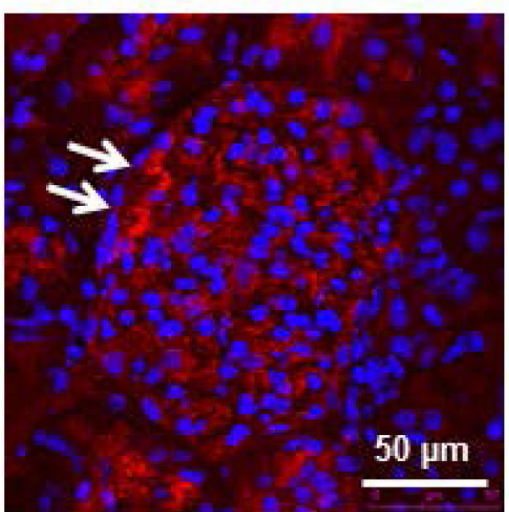

B

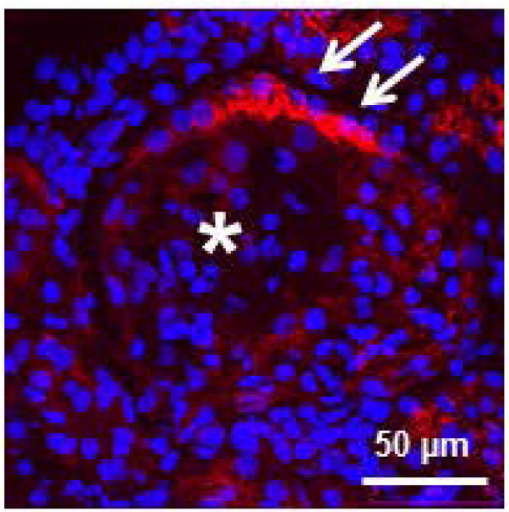

C

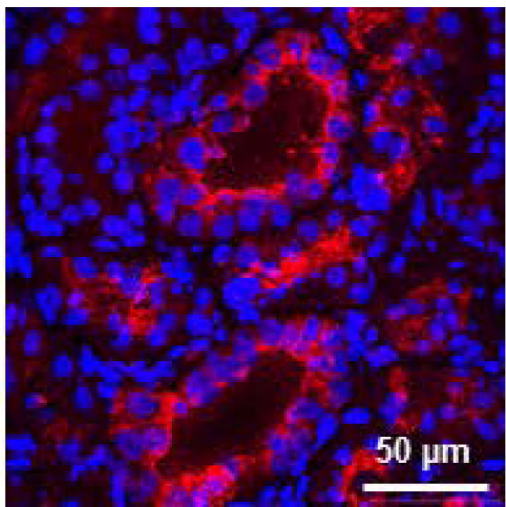

CD44/DAPI
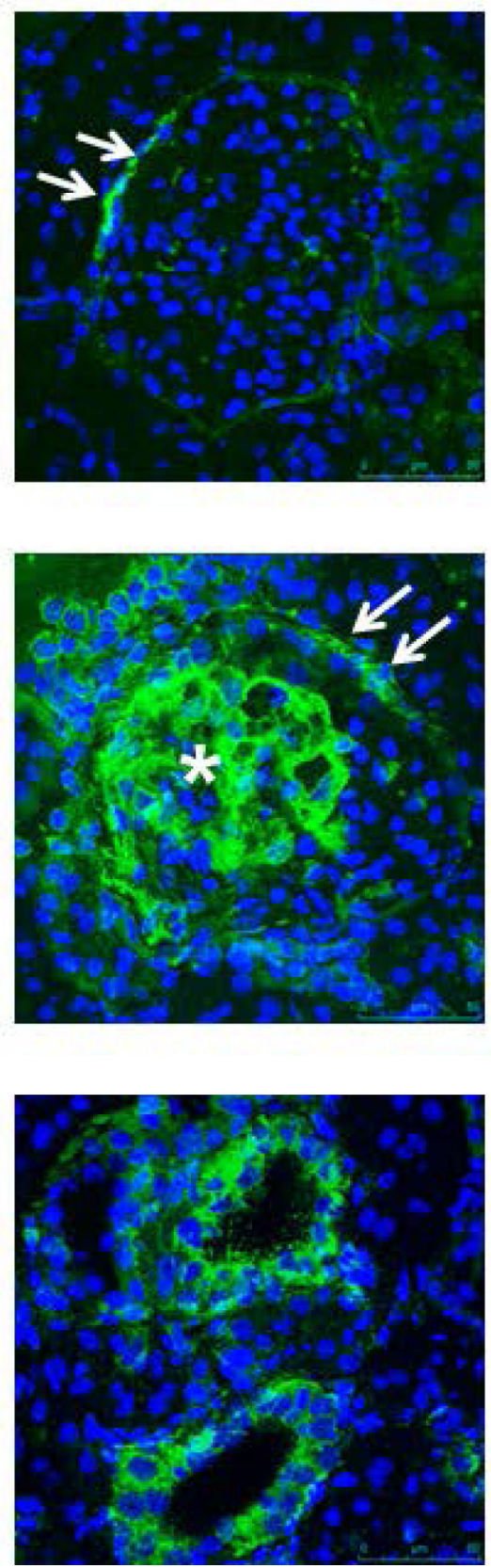

Merge
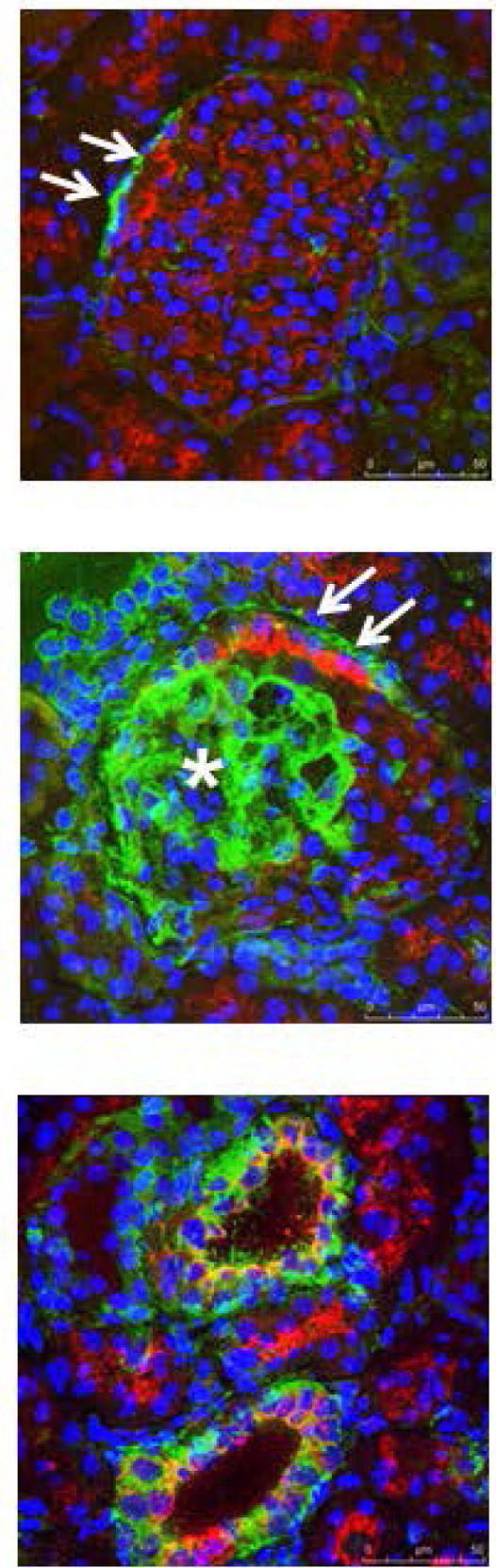

Figure 7. Megalin and CD44 staining in the diabetic rat kidney.

Immunostaining of Zucker rat kidney sections confirmed megalin expression by glomerular podocytes (A-B) and proximal tubular cells $(\mathbf{C})$. Within Bowman's capsule, bright megalin red staining was also observed on the apical membrane of activated PECs with CD44 (green) on the basolateral membrane (A \& B, white arrow). In severely damaged glomeruli, only weak megalin staining was detected in CD44-positive glomerular tuft cells (B, white star). Moreover, substantial CD44 staining was also detected in the dilated proximal tubules of diabetic rats $(\mathbf{C})$. 

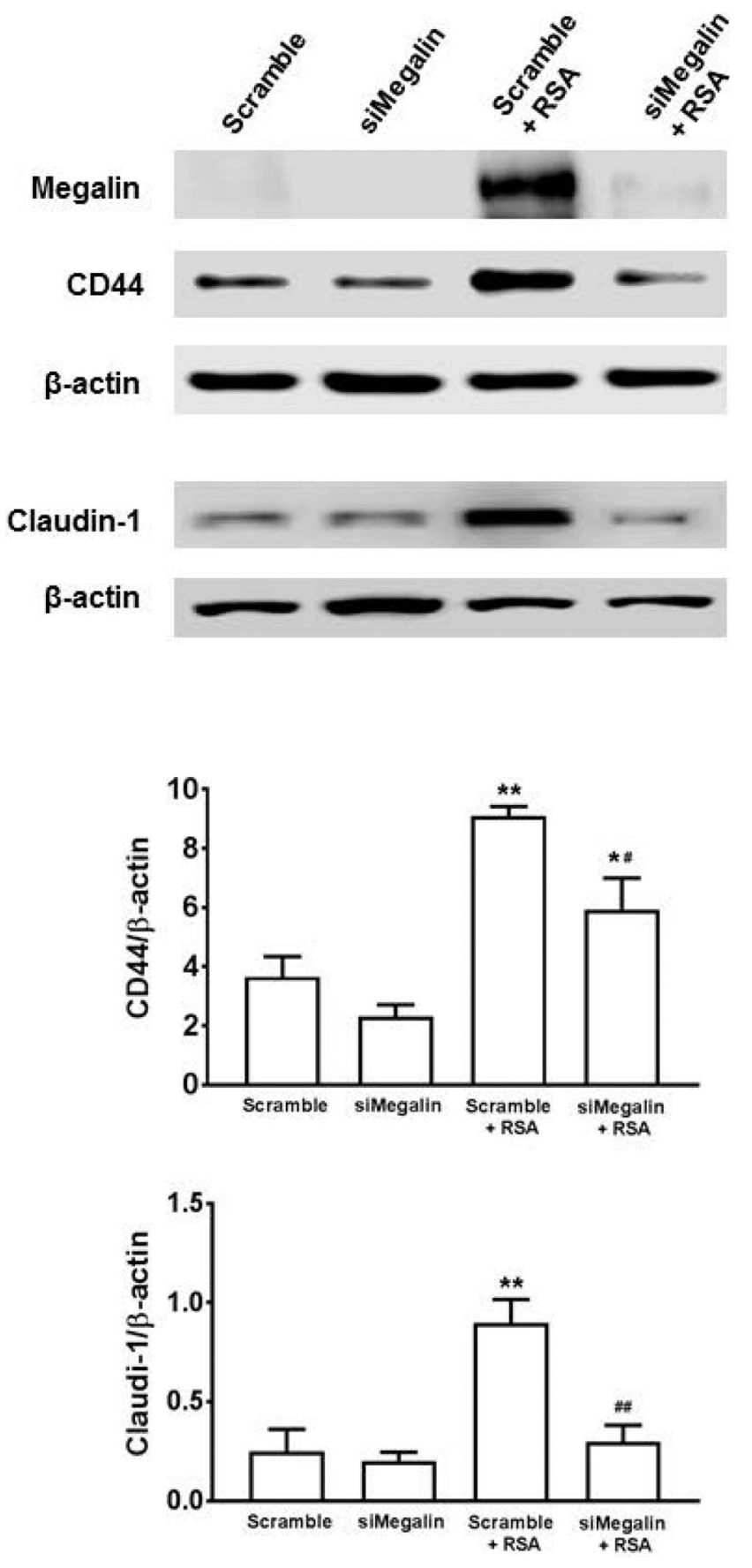

Figure 8. Knockdown of megalin inhibited albumin-induced CD44 and claudin-1 expression in cultured PECs.

Megalin protein was significantly higher when the cells were exposed to RSA $(0.5 \mathrm{mg} / \mathrm{ml})$ for 24 hours in the presence of scramble siRNA. Knockdown of megalin by siRNA interference significantly attenuated albumin-induced CD44 and claudin-1 protein expression. Quantitative data (mean \pm SEM) are summarized from $n=3-5$ separate experiments. ${ }^{*} P<0.05$, ** $P<0.01$ vs. unstimulated groups; ${ }^{\#} P<0.05$, ${ }^{\#} P<0.01$ vs. albuminstimulated scramble group. 


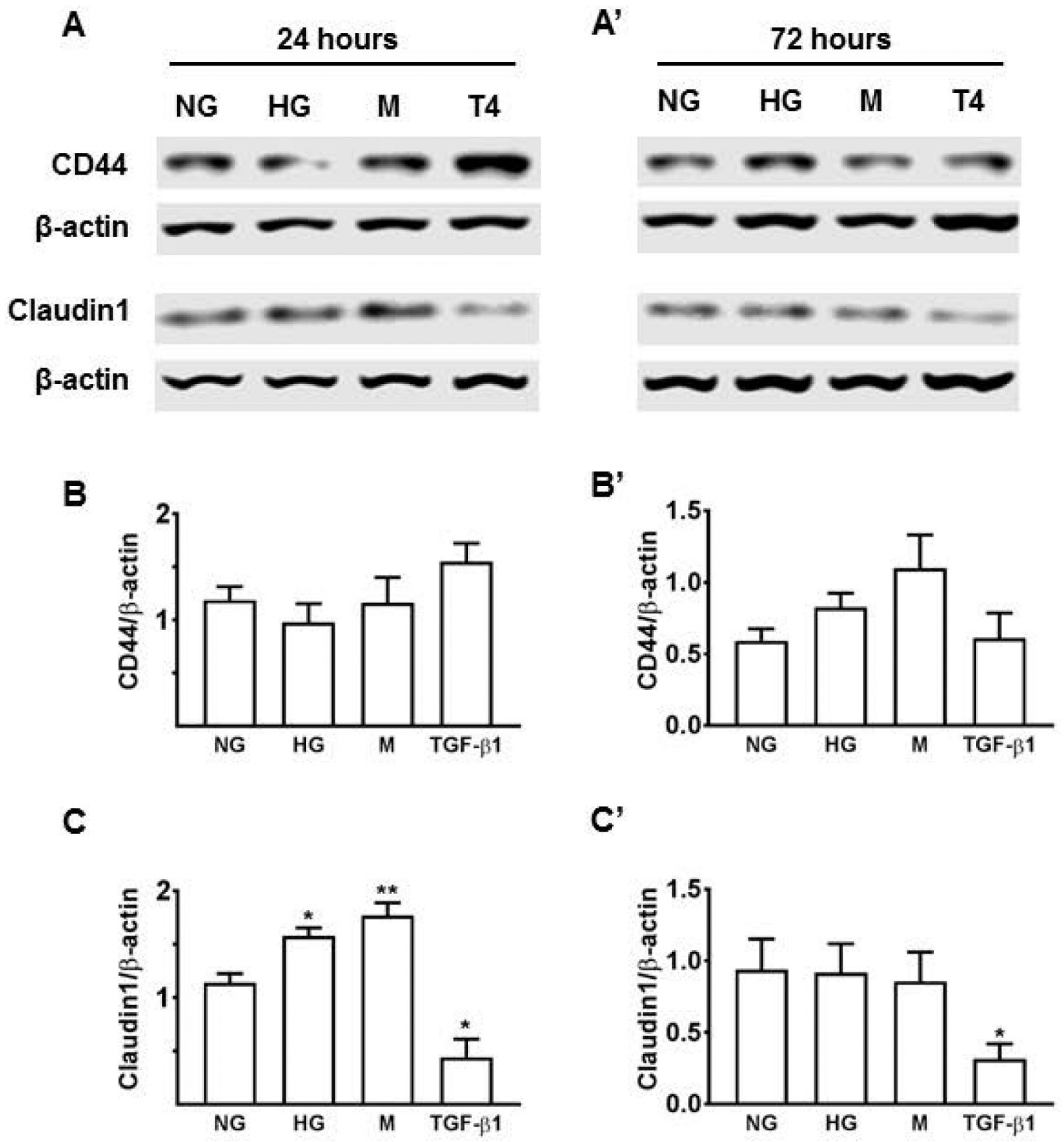

Figure 9. Effects of high glucose and TGF- $\beta 1$ on CD44 and claudin-1 protein expression in primary PECs.

(A-A') Representative Western blot images of CD44 and claudin-1 in primary cultured rat PECs treated with normal glucose (NG), high glucose (HG), mannitol (M), or TGF- $\beta 1$ (T4) for 24 (A) or 72 (A') hours. Quantitative data in B-C (24 hour) and B'-C' (72 hour) are summarized from $\mathrm{n}=3-5$ separate experiments. Values are mean \pm SEM. $* P<0.05, * * P<0.01$ vs. normal glucose control. 